\title{
PQRS and the MACRA: Value-Based Payments Have Moved from Concept to Reality
}

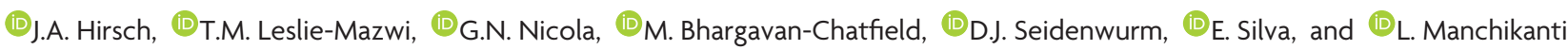

$F$ rom its beginnings in 1965, Medicare costs quickly exceeded initial projections, prompting policy makers to enact a number of remedies during the history of the program. The most recent example is the Medicare Access and Children's Health Insurance Program (CHIP) Reauthorization Act of 2015 (MACRA). ${ }^{1}$ Embedded within the MACRA is the concept of quality metrics being used to assess performance. This concept is not new in American health care delivery. This article will explore the evolution of Medicare physician payments and the concurrent development of this quality-reporting element. Table 1 provides a glossary of terms that are commonly used in the discussion of delivery of care quality.

\section{SELECTED HISTORY}

Medicare was established as part of President Johnson's great society in 1965. A mere 10 years later, costs had grown alarmingly; this growth prompted the enactment of several measures to both control and regulate expenses. In 1975, growth in physician payments was statutorily limited on the basis of the Medicare Economic Index (MEI), which was devised as means of measuring and controlling practice growth. ${ }^{2}$ In 1984, Congress attempted further spending control by an annual adjustment in professional fees. ${ }^{2}$ The following year researchers at Harvard began a multiyear effort published in 1988 proposing a resource-based relative value system that established a national relativity scale for all physician services. ${ }^{3}$ This was incorporated into the Medicare Physician Payment System in 1989. ${ }^{4}$ Then in 1997, the Balanced Budget Act created the Sustainable Growth Rate Formula (SGR) under which Medicare physician payments were directly linked to the United States economy, the covered population, health care innovation, and overall inflation. ${ }^{2,5,6}$

From the Departments of Neuroendovascular Imaging (J.A.H., T.M.L.-M.), Radiology (J.A.H.), and Neurology (T.M.L.-M.), Massachusetts General Hospital, Boston, Massachusetts; Hackensack Radiology Group (G.N.N.), River Edge, New Jersey; American College of Radiology (M.B.-C.), Reston, Virginia; Department of Radiology (D.J.S.), Sutter Medical Group, Sacramento, California; South Texas Radiology Group (E.S.), San Antonio, Texas; and Pain Management Center (L.M.), Paducah, Kentucky.

Please address correspondence to T.M. Leslie-Mazwi, MD, Department of Neuroendovascular Imaging, Massachusetts General Hospital, GRB 2-241, 55 Fruit St, Boston, MA 02114; e-mail: tleslie-mazwi@mgh.harvard.edu; @JoshuaAHirsch

三 Indicates article with supplemental on-line table.

http://dx.doi.org/10.3174/ajnr.A4936
Despite these incremental efforts to control spending, with time costs exceeded the SGR targets, prompting annual reductions in physician payment. These reductions arose due to a number of factors captured collectively by the economic phenomenon known as Baumol Disease - that is, the declining relative productivity of the personal services sector of the economy, in which productivity is largely determined by the amount of time that one person spends with another. Medicine is one of the sectors most affected. The amount of time whereby medical visits can be shortened is self-limited before the quality of the interaction is adversely affected. This limit results in an ever greater share of the gross domestic product being diverted to personal services compared with sectors such as manufacturing, telecommunications, and data processing in which, in relative terms, productivity has continued to increase per hour worked. As such, physician costs rise faster than gross domestic product. The magnitude of the discrepancy is further accentuated by a combination of factors, including fee-for-service payment methodologies, third party payment, first dollar coverage with supplemental insurance, and the behavioral offset among providers. ${ }^{7}$

Reversing the annual mandated reductions in physicians' payments became an important focus of medical professional societies (including the American Society of Neuroradiology and multiple additional radiology societies), an effort that has stretched for multiple consecutive years. ${ }^{8,9}$ Concurrently, an increasing focus was being applied to the need to improve quality within the health care system. The Institute of Medicine (IOM) published the landmark report Crossing the Quality Chasm: A New Health System for the 21st Century in 2001. ${ }^{10}$ This highlighted challenges in delivering consistent quality of care across the United States and proposed methods to improve care quality. A key approach was "pay for performance," using financial incentives to help develop better quality and value. ${ }^{11}$ The IOM report provided momentum to legislatively mandate "pay for performance," prompting the emergence of new programs. ${ }^{12}$ One of these, the Physician Quality Reporting System (PQRS), was established as the Physician Quality Reporting Initiative under the 2006 Tax Relief and Health Care Act (TRHCA), based on the notion that health care providers should be able to provide quality and outcome information not otherwise readily available from existing 
Table 1: Glossary of terms commonly used in literature regarding care delivery and quality metrics

ABR: American Board of Radiology

ACA: Patient Protection and Affordable Care Act

ACO: Accountable Care Organization

ACR: American College of Radiology

AMA: American Medical Association

API: Application program interfaces

APM: Alternative Payments Model

ASNR: American Society of Neuroradiology

CEHRT: Certified EHR Technology

CHIP: Children's Health Insurance Program

CMS: Centers for Medicare \& Medicaid Services

CPIA: Clinical Practice Improvement Activities

EHR: Electronic Health Record

EP: Eligible Professionals

HCPLAN: Health Care Payment Learning Action Network

IOM: Institute of Medicine

MACRA: Medicare Access and CHIP Reauthorization Act

MAP: Measures Application Partnership

MEI: Medicare Economic Index

MIPS: Merit-Based Incentive Payment System

MPFS: Medicare Physician Fee Schedule

NQF: National Quality Forum

NQS: National Quality Strategy

NRDR: National Radiology Data Registry

OBRA: Omnibus Budget Reconciliation Act

PQI: Practice Quality Improvement

PQRS: Physician Quality Reporting System

QCDRs: Qualified Clinical Data Registries

QRUR: Quality and Resource Use Reports

SCHIP: State Children's Health Insurance Program

SGR: Sustainable Growth Rate Formula

TRHCA: Tax Relief and Health Care Act

Medicare claims. ${ }^{13}$ Early data suggested limited eligible provider participation. ${ }^{14}$

\section{THE CURRENT FIELD OF PLAY}

The Patient Protection and Affordable Care Act of 2010 (ACA) brought in the next chapter of physician quality reporting. ${ }^{15}$ The ACA included specific language that mandated the Centers for Medicare \& Medicaid Services (CMS) incorporate Quality alongside Cost and Resource Use as an element in considering payment. ${ }^{16}$ The Secretary of the Department of Health and Human Services, Sylvia Burwell, published the Obama administration's payment policy goals in early $2015,{ }^{17}$ describing the transition to payments based on quality and value through alternative payment model participation. The goals were impressive in both their scale and speed of implementation: $85 \%$ of all Medicare fee-for-service payments were to be tied to quality or value by 2016 , and $90 \%$, by 2018. ${ }^{18}$ This statement occurred in the context of several CMS initiatives founded on value-based approaches to providing health care. ${ }^{19-21}$

Congress took advantage of a budgetary opportunity produced by decreased health care inflation (due to the economic downturn and slow economic growth) and replaced the SGR with the MACRA in early 2015. ${ }^{1}$ This bipartisan legislation left little doubt about the value-oriented future of health care in the United States during 2015-2021 and beyond. ${ }^{22,23}$

The MACRA attempts to align various preexisting performance programs, consolidating aspects of the PQRS, Value-Based
Payment Modifier Program, and the Meaningful Use initiative with which many readers will be familiar. The MACRA defines 2 methods for payment to enable the transition toward the goal of paying for better care value. The first is Alternate Payment Models (APMs); the second is the Merit-Based Incentive Payment System (MIPS). Essentially APMs offer novel alternatives to pay health care providers for the care they give Medicare beneficiaries and encompasses Accountable Care Organizations (ACOs), PatientCentered Medical Homes, and bundled payment models. MIPS, detailed further below, is particularly important to understand because MIPS applies to physicians still billing under fee-for-service, initially likely most radiologists.

\section{MERIT-BASED INCENTIVE PAYMENT SYSTEM}

Under MIPS, eligible professionals (EP) will receive a composite performance score based on 4 performance categories: Quality, Resource Use, Meaningful Use (since renamed “Advancing Care Information”), and Clinical Practice Improvement Activities (CPIA). The EP designation encompasses physicians (including podiatrists and chiropractors), nurse practitioners, physician assistants, therapists, clinical nurse specialists, dietitians, clinical social workers, and others involved in direct patient care. Quality in this context refers directly to PQRS (ie, PQRS should be viewed as 1 of the 4 components of the MACRA). The MACRA, largely through MIPS, attempts to align these disparate performance programs. One important method of accomplishing this alignment is the development and use of Qualified Clinical Data Registries (QCDRs). QCDRs collect medical data for data tracking to affect performance improvement in patient care and are important in that participation in QCDRs may satisfy portions of all 4 performance categories of the MIPS (if the reporting registries are appropriately designed). Compliance with QCDRs stands to completely satisfy the "Quality" component of MIPS and can be used from 2015 to 2018 to satisfy reporting requirements in the years preceding MACRA. The current proposed weighting for 2019, which can be modified by the CMS going forward, is $50 \%$ for Quality measures, $10 \%$ for Resource Use, $25 \%$ for Advancing Care Information, and 15\% for CPIA. ${ }^{24}$

At first glance, MIPS appears to be the preexisting CMS quality programs reconfigured; however, a recent alternate position presents MIPS as one of the progressive classifications leading to the end goal of population-based payments as the dominant payment paradigm of the US health care system. ${ }^{25,26}$ In this context, MIPS may allow fee-for-service participants to collect relevant data that may be useful, while the provider restructures services with a focus on quality, value, and practice improvement, all metrics considered important in providing accountable care.

The categories under MIPS also include what most stakeholders in APMs care about-quality, prudent resource use, interoperability, and a culture of quality improvement. Therefore, any practice using MIPS for some of its patients can use the same activities to negotiate contracts within APM plans, such as ACOs, or with other payers on the basis of their performance and the value of the care they deliver. 


\section{DIRECT FINANCIAL IMPLICATIONS}

Demonstration of effort directed toward quality and value has long been tied to financial consequences for physicians, radiologists included. It is important to keep this in mind in the context of the current expectations. The 2006, TRHCA allowed a $1.5 \%$ bonus payment for EPs who satisfactorily reported quality measures for services that were relevant to Medicare. This was simply a reporting standard; no data were submitted or required, and payments were capped. In 2007, the Medicare, Medicaid, and State Children's Health Insurance Program (SCHIP) Extension Act authorized continuation of this incentive for 2008 and 2009. ${ }^{1}$ The 2008 Medicare Improvements for Patients and Providers Act increased the potential incentive payment to $2 \%$ and made PQRS permanent. $^{27}$

The pendulum swung back the other way in 2010. The ACA, while championing value approaches, mandated a decrease with time in the PQRS incentive payment from the $2 \%$ peak established in 2008. ${ }^{28}$ The year 2011 saw the potential bonus payment decreased to a maximum of $1 \%$ of the total allowed charges for professional services. From 2012 to 2014, the maximum benefit was capped at $0.5 \%$. Per the ACA, in 2015, negative payment adjustments (or, in other words, penalties) began if the quality measure reporting requirements were not met, rising to potentially $2 \%$ of Part B-covered professional services. Medicare penalties and bonuses for any given year are determined by reporting in a prior performance period. ${ }^{29}$

The MACRA further complicates the mathematics of bonuses or penalties around quality metrics. The legislation mandates positive $0.5 \%$ conversion factor updates affecting all Medicare Physician Fee Schedule (MPFS) payments until 2019 and then no increase or decrease until 2026. Payments will also be adjusted on the basis of a physician's composite performance score. The 4 components of Quality, Resource Use, Advancing Care Information, and CPIA are scored on a 100-point basis with aggregates compared with other eligible providers. As of 2019, if a provider is on par with the mean (or median) base performance measure, referred to as the threshold score, there is no bonus or penalty. If a physician rises above or falls below the threshold score, there will be positive or negative adjustments, respectively. The magnitude of these adjustments increases (or decreases) from 4\% in 2019 to $9 \%$ in 2022 and thereafter. An additional $\$ 500$ million is potentially available from calendar years 2019 to 2024 for individual providers or groups that perform exceptionally well. ${ }^{22}$ For providers, therefore, there is great financial incentive to both deliver and document quality care. It is important to initiate efforts to meet these requirements in a timely and thoughtful manner, to maximize the chance of practice success.

\section{RULES OF ENGAGEMENT}

To satisfy a specific PQRS measure, one must successfully report a minimum percentage of the total patient encounters to which the measure applies. That minimum percentage stands at 50\% currently. The numerator equals the number of services satisfied under the PQRS measure being studied. The denominator represents the total number of eligible cases/patient population associated with the quality measure. ${ }^{30}$
On what measures should you as an EP choose to be judged? Much depends on measures available and information currently gathered in your practice. Measure development is an important aspect of the PQRS program. The Affordable Care Act mandated the establishment of a national strategy for quality improvement in health care, which is dubbed the National Quality Strategy (NQS). The NQS informs measure development based on improved and affordable care, focusing on 6 different domains, including patient safety, person- and caregiver-centered experience and outcomes, care coordination, effective clinical care, population health, and cost reduction.

Remembering the reporting need for a minimum percentage of the total patient encounters to which the measure applies, EPs then select the measures for which they would prefer to be held accountable, ideally choosing those most applicable to them, focused on the various domains. In 2016, there are almost 300 possible measures, including some that are uniquely suited to radiology.

\section{MEASURES FROM WHICH TO SELECT}

Quality measures are a moving target. For an EP, staying abreast with current developments and understanding their historical context is of great import. Traditionally, creation of a metric was an arduous task requiring ample clinical evidence of effectiveness before approval by the governing body of such metrics, the National Quality Forum (NQF). With the advent of QCDRs, CMS has shown the willingness to explore broader criteria for the creation of metrics and offers opportunity for use of clinical data registry measures in the PQRS. This feature has provided the radiology community a real avenue for experimentation in territories that were off limits using the older NQF approach, and therefore a certain flexibility. The On-line Table provides examples of current PQRS measures that could be selected, with their definitions.

Other options exist besides selecting measures from established PQRS metrics, specifically if a comfortable fit is not found in that list of options. The American College of Radiology (ACR) National Radiology Data Registry (NRDR) (acr.org/nrdr) is a clinical data registry serving as the umbrella for a collection of data bases covering a range of radiology-specific measures. ${ }^{31}$ Clinical data registries such as these self-nominate to CMS to become QCDRs for enabling PQRS participation. QCDRs selfnominate annually, and CMS reviews the measures for acceptability and allows the "non-PQRS measures" of the QCDRs defined in the registry to be reported for PQRS credit. CMS reviewing non-PQRS measures for PQRS credit presents an alternate route for a measure to be selected, implemented, and met. A QCDR may also offer PQRS measures to be reported as well. From across the NRDR, a selection of measures can be chosen for use in the QCDRs. The QCDRs provide a pathway for trying and testing measures while eligible professionals receive credit for monitoring and reporting them. Table 2 provides examples of categories of QCDRs that provide a focus for recording quality-improvement effort.

In addition, CMS evaluates measures that are not NQF-endorsed and accepts them for use in PQRS with recommendations from the Measures Application Partnership (MAP). The MAP is a 
Table 2: Select examples from the Qualified Clinical Data Registry ${ }^{a}$

\begin{tabular}{|c|c|c|c|c|}
\hline $\begin{array}{l}\text { Non-PQRS } \\
\text { Measure }\end{array}$ & Measure Title & Description of Measure & NQS Domain & NRDR Data Base \\
\hline ACRad 3 & $\begin{array}{r}\text { Screening Mammography } \\
\text { Cancer Detection Rate }\end{array}$ & $\begin{array}{l}\text { Fraction of screening mammograms } \\
\text { interpreted as abnormal with } \\
\text { tissue diagnosis of cancer } \\
\text { confirmed within } 12 \text { mo }\end{array}$ & $\begin{array}{l}\text { Effective Clinical } \\
\quad \text { Care }\end{array}$ & $\begin{array}{l}\text { National Mammography } \\
\text { Database }\end{array}$ \\
\hline ACRad 9 & $\begin{array}{l}\text { Median Dose-Length } \\
\text { Product for CT Head/ } \\
\text { Brain Without Contrast }\end{array}$ & $\begin{array}{l}\text { Median dose-length product for CT } \\
\text { head/brain without contrast, } \\
\text { measured at a facility/group } \\
\text { level for all physicians who } \\
\text { interpret CT scans }\end{array}$ & Patient Safety & Dose Index Registry \\
\hline ACRad 14 & $\begin{array}{l}\text { Participation in a National } \\
\text { Dose Index Registry }\end{array}$ & $\begin{array}{l}\text { No. of CT examinations performed } \\
\text { at the facility and submitted to } \\
\text { the Dose Index Registry }\end{array}$ & Patient Safety & Dose Index Registry \\
\hline ACRad 17 & $\begin{array}{l}\text { Report Turnaround Time: } \\
\text { MRI }\end{array}$ & Mean MRI report turnaround time & $\begin{array}{l}\text { Communication } \\
\text { and Care }\end{array}$ & $\begin{array}{l}\text { General Radiology Improvement } \\
\text { Database }\end{array}$ \\
\hline ACRad 20 & $\begin{array}{l}\text { CT IV Contrast Extravasation } \\
\text { Rate }\end{array}$ & $\begin{array}{l}\text { Percentage of CT examinations } \\
\text { with contrast performed that } \\
\text { resulted in extravasation, } \\
\text { measured at a facility/group } \\
\text { level for all physicians who } \\
\text { interpret CT scans }\end{array}$ & Patient Safety & $\begin{array}{l}\text { General Radiology Improvement } \\
\text { Database }\end{array}$ \\
\hline ACRad 23 & $\begin{array}{l}\text { Lung Cancer Screening } \\
\text { Abnormal Interpretation } \\
\text { Rate }\end{array}$ & $\begin{array}{l}\text { The percentage of screenings for } \\
\text { lung cancer interpreted as } \\
\text { positive }\end{array}$ & $\begin{array}{l}\text { Efficiency and } \\
\text { Cost }\end{array}$ & Lung Cancer Screening Registry \\
\hline
\end{tabular}

Note:-ACRad indicates American College of Radiology.

${ }^{a}$ These represent non-PQRS measures. QCDRs collect medical and/or clinical data for the purpose of patient and disease tracking. Data from the National Radiology Data Registry. ${ }^{31}$

public-private partnership coordinated by the NQF to provide input from stakeholders on proposed measures and to build consensus around them. The MAP therefore represents a potential target for advocacy and lobbying from the radiology community. While the goal for CMS is to be able to work toward NQF endorsement for all these measures, having them in use provides radiology with the data necessary to seek endorsement in the future. One series of examples of such explorations are the new 2016 CMS-approved PQRS measures of incidental findings in the liver, kidneys, adrenal glands, and thyroid. These incidental findings have the potential to cause meaningful downstream costs with no change in patient morbidity or mortality, and hence poor resource use. The CMS with the MAP developed metrics created around these incidental radiographic findings to allow measurement of adherence to expert opinion and to serve as a potential benchmark for those who wish to improve their clinical practice, goals identical to the MIPS performance categories of "Resource Use" and "Clinical Practice Improvement"! ${ }^{32}$

\section{CONSIDERATIONS WITH THE EVOLUTION OF MEASURES}

Traditionally, PQRS measures for radiology have been process measures; clinical actions or data supporting successful reporting on specific measures are generally not submitted to CMS but must be documented in the medical record. For example, measure 145 (On-line Table) requires the reporting of fluoroscopy dose indices or the time and number of images, but the actual data are not directly submitted to CMS. There has been an increasing emphasis on reporting outcome measures. Outcomes are defined broadly to include intermediate outcomes and the patient experience of care, for example, recall rates or cancer-detection rates for mammography and average report turnaround times. It is challenging to measure such outcomes within the constraints of claims reporting, and QCDRs offer many more options for monitoring and reporting measures like these because they are based on broader clinical data. This consideration may be important in selecting measures. Outcome-focused measures may have greater longevity ultimately, though they may have greater implementation needs for initially establishing them.

Most efficiently, EPs would meet multiple regulatory requirements through the same effort. As an example, all of the ACR NRDR data bases have American Board of Radiology (ABR)approved Practice Quality Improvement (PQI) projects associated with them. Registry participation by itself has recently been approved by the ABR as a PQI activity eligible for credit toward Maintenance of Certification Part 4, and PQI activities closely match the MIPS description of clinical practice improvement activities. Several of the NRDR data bases accept data by electronic upload or transmission or through Web service application program interfaces (APIs). Furthermore, if these data are extracted from a certified electronic health record (EHR) technology (CEHRT), the submission meets a Public Health Reporting objective, under Advancing Care Information. Because QCDRs support multiple components of MIPS for the same activity, they feature prominently in MACRA. ${ }^{22}$

The transparency of this quality effort will also evolve. Since the 2013 performance period, CMS has been providing EPs and groups with confidential feedback reports: Quality and Resource Use Reports (QRUR) that allow PQRS participants to compare themselves with other groups of providers on the basis of specific episodes of care. The QRUR give group practices an opportunity to "preview" their outcomes in the Value Modifier program. The 
Learn about quality measures and the impact on your practice, including effort made by the practice to date

Select measures for which to be accountable (PQRS and QCDR) Ensure method presently exists to record the metrics required for the selected measures and if not then establish one

Assess whether current EHR meets criteria for a CEHRT; if so, configure to enable direct database reporting to www.acr.org/nrdr

Access QRUR to evaluate performance compared with other groups, including public reporting from CMS

Adjust accordingly (either data collection or metric chosen)

Adjust budgeting on the basis of impact quality performance will have on practice finances
Read articles and Web sites (including material referenced in this article), engage practice administration, share insights with other providers

www.acr.org/nrdr, www.cms.gov

Discuss with practice administration

EHR vendor, hospital, or practice information technology service

https://www.cms.gov/medicare/quality-initiatives-patientassessment-instruments/physician-compare-initiative/

Practice administration

Practice administration

Note:-PQRS indicates Physician Quality Reporting System; QCDR, Qualified Clinical Data Registry; EHR, Electronic Health Record; CEHRT, Certified EHR Technology; QRUR, Quality and Resource Use Reports.

reports are mandated to be more frequent and timely under MACRA. CMS is additionally stepping into publicly reporting more measures for a broader group of providers each year via Physician Compare. ${ }^{33}$

Satisfactory PQRS reporting in 2015 and 2016 will avoid the 2017 and 2018 negative payment adjustments, respectively. Starting in 2019, payment will be adjusted on the basis of performance within the MIPS. ${ }^{32}$ As indicated above, there will no longer be any incentive or penalty for just reporting quality measures; incentives and penalties will be assessed on aggregate performance across the 4 specified MIPS categories, similar to how quality and cost performance are currently evaluated in the Value Modifier program. Physicians or groups with performance significantly better than average will have positive adjustments. Physicians or groups who do not perform as well as average will have downward adjustments. Table 3 provides an approach to preparing for this change in health care reimbursement.

\section{SUMMARY}

Medicare is in a period of transition. Approximately 10 years ago, the 2006 Tax Relief and Health Care Act established the Physician Quality Reporting System and eligible providers were given an opportunity to earn incentives by successfully reporting quality metrics. The Affordable Care Act brought important refinements to PQRS, including the introduction of negative adjustments for nonparticipation. The MACRA recognized that one of the challenges facing practitioners was the disparate nature of the various CMS programs designed to facilitate quality of care and measure resource use. Going forward, these metrics will be aggregated into a single numeric score, which may be attractive to providers. Understanding this evolution is important for radiologists, given the potential modification of provider payments over a range of $18 \% \pm 9 \%$ based on successful participation in these programs.

\section{ACKNOWLEDGMENTS}

We wish to acknowledge Judy Burleson for her invaluable assistance with the content of Table 2 and the On-line Table, and suggestions for the manuscript.

Disclosures: Joshua A. Hirsch—UNRELATED: Consultancy: Medtronic (interventional spine), Codman Neurovascular (Data and Safety Monitoring Board), CareFusion (single event $<36$ months ago, teaching a non-Continuing Medical Education course). Mythreyi Bhargavan-Chatfield - UNRELATED: Employment: American College of Ra- diology. David J. Seidenwurm—UNRELATED: Consultancy: medical legal (personal injury, medical liability); Board Membership: Radiological Associates of Sacramento; Employment: Sutter Health; Grants/Grants Pending: Stanford Institutes of Medicine Summer Research Program * (imaging appropriateness); Payment for Lectures (including service on Speakers Bureaus): State University of New York, Stanford; Stock/Stock Options: RASMG; Travel/Accommodations/Meeting Expenses Unrelated to Activities Listed: American College of Radiology, National Quality Forum, The Alliance; Other: Sutter Medical Group, Sutter Medical Foundation. Laxmaiah Manchikanti-UNRELATED: Consultancy: Semnur Pharmaceuticals (limited amount of \$1400); Employment: Pain Management Center of Paducah. *Money paid to the institution.

\section{REFERENCES}

1. The Medicare Access and CHIP Reauthorization Act of 2015. https:// www.congress.gov/bill/114th-congress/house-bill/2. Accessed June 2, 2015

2. Manchikanti L, Singh V, Caraway DL, et al. Medicare physician payment systems: impact of 2011 schedule on interventional pain management. Pain Physician 2011;14:E5-33 Medline

3. Hsiao WC, Braun P, Kelly NL, et al. Results, potential effects, and implementation issues of the Resource-Based Relative Value Scale. JAMA 1988;260:2429-38 CrossRef Medline

4. Hirsch JA, Silva E 3rd, Nicola GN, et al. The RUC: a primer for neurointerventionalists. J Neurointerv Surg 2014;6:61-64 CrossRef Medline

5. Seidenwurm DJ, Burleson JH. The Medicare conversion factor. AJNR Am J Neuroradiol 2014;35:242-43 CrossRef Medline

6. Balanced Budget Act of 1997. https://www.gpo.gov/fdsys/pkg/ PLAW-105publ33/content-detail.html. Accessed July 1, 2015

7. Baumol WJ. The Cost Disease: Why Computers Get Cheaper and Health Care Doesn't. New Haven: Yale University Press; 2012:16-32

8. Hirsch JA, Rosman DA, Liu RW, et al. Sustainable growth rate 2013: time for definitive intervention. J Neurointerv Surg 2013;5:382-86 CrossRef Medline

9. Hirsch JA, Manchikanti L. The sustainable growth rate: a 2014 update. J Neurointerv Surg 2014;6:411-12 CrossRef Medline

10. Committee on Quality of Health Care in America, Institute of Medicine. Crossing the Quality Chasm: A New Health System for the 21st Century. Washington DC: National Academies Press; 2001

11. Committee on Redesigning Health Insurance Performance Measures, Payment, and Performance Improvement Programs and Board on Health Care Services. Rewarding Provider Performance: Aligning Incentives in Medicare (Pathways to Quality Health Care Series). Washington DC: National Academies Press; 2007

12. Tompkins CP, Higgins AR, Ritter GA. Measuring outcomes and efficiency in Medicare value-based purchasing. Health Aff (Millwood) 2009;28:w251-61 CrossRef Medline

13. Tax Relief and Health Care Act of 2006. https://www.gpo.gov/fdsys/pkg/ PLAW-109publ432/html/PLAW-109publ432.htm. Accessed April 15, 2016 
14. Centers for Medicare \& Medicaid Services, Department of Health and Human Services. Physician Quality Reporting Initiative: 2007 Reporting Experience. December 3, 2008; https://www.cms.gov/ Medicare/Quality-Initiatives-Patient-Assessment-Instruments/PQRS/ downloads/PQRI2007ReportFinal12032008CSG.pdf. Accessed April 14, 2016

15. Patient Protection and Affordable Care Act. 2010. https://www.hhs. gov/healthcare/about-the-law/read-the-law/index.html. Accessed April 14, 2016

16. Manchikanti L, Hirsch JA. Patient Protection and Affordable Care Act of 2010: a primer for neurointerventionalists. J Neurointerv Surg 2012;4:141-46 CrossRef Medline

17. Burwell SM. Setting value-based payment goals: HHS efforts to improve U.S. health care. N Engl J Med 2015;372:897-99 CrossRef Medline

18. Hirsch JA, Leslie-Mazwi TM, Barr RM, et al. The Burwell roadmap. J Neurointerv Surg 2016;8:544-46 CrossRef Medline

19. Hirsch JA, Leslie-Mazwi TM, Barr RM, et al. The Bundled Payments for Care Improvement Initiative. J Neurointerv 2016;8:547-48 CrossRef Medline

20. Hirsch JA, Leslie-Mazwi TM, Meyers PM, et al. Accountable care. J Neurointerv 2015 Jun 17. [Epub ahead of print] Medline

21. Meehan TM, Harvey HB, Duszak R Jr, et al. Accountable Care Organizations: what they mean for the country and for neurointerventionalists. J Neurointerv Surg 2016;8:654-57 CrossRef Medline

22. Hirsch JA, Leslie-Mazwi TM, Patel AB, et al. MACRA: background, opportunities and challenges for the neurointerventional specialist. J Neurointerv Surg 2016;8:868-74 CrossRef Medline

23. Hirsch JA, Harvey HB, Barr RM, et al. Sustainable growth rate repealed, MACRA revealed: historical context and analysis of recent changes in Medicare physician payment methodologies. AJNR Am J Neuroradiol 2016;37:210-14 CrossRef Medline

24. Department of Health and Human Services, Centers for Medicare \& Medicaid Services. Medicare Program: Merit-Based Incentive Payment System (MIPS) and Alternative Payment Model (APM) Incentive under the Physician Fee Schedule, and Criteria for PhysicianFocused Payment Models. 2016; https://s3.amazonaws.com/publicinspection.federalregister.gov/2016-10032.pdf. Accessed May 17, 2016
25. Centers for Medicare \& Medicaid Services. Health Care Payment Learning and Action Network. https://innovation.cms.gov/initiatives/ Health-Care-Payment-Learning-and-Action-Network/. Accessed April 14,2016

26. Alternative Payment Model Framework and Progress Tracking (APM FPT) Work Group. Alternative Payment Model (APM) Framework: Final White Paper. https://hcp-lan.org/workproducts/apm-white paper.pdf. Accessed April 14, 2016

27. Anumula N, Sanelli PC. Physician Quality Reporting System. AJNR Am J Neuroradiol 2011;32:2000-01 CrossRef Medline

28. Manchikanti L, Hirsch JA. Obama health care for all Americans: practical implications. Pain Physician 2009;12:289-304 Medline

29. United States Government. Federal Register. https://www.gpo.gov/ fdsys/pkg/FR-2015-11-16/pdf/2015-28005.pdf. Accessed April 12, 2016

30. Manchikanti L, Hammer M, Benyamin RM, et al. Physician Quality Reporting System (PQRS) for interventional pain management practices: challenges and opportunities. Pain Physician 2016;19: E15-32 Medline

31. National Radiology Data Registry. http://www.acr.org/ /media/ ACR/Documents/PDF/QualitySafety/NRDR/2014\%20NonPQRS\% 20QCDR\%20Measures.pdf. Accessed April 9, 2016

32. Centers for Medicare \& Medicaid Services. The Merit-Based Incentive Payment System (MIPS) \& Alternative Payment Models (APMs): Delivery System Reform, Medicare Payment Reform, \& the MACRA. https://www.cms.gov/Medicare/Quality-Initiatives-Patient-AssessmentInstruments/Value-Based-Programs/MACRA-MIPS-and-APMs/ MACRA-MIPS-and-APMs.html. Accessed April 10, 2016

33. Centers for Medicare \& Medicaid Services. Physician Compare Initiative. https://www.cms.gov/medicare/quality-initiatives-patientassessment-instruments/physician-compare-initiative/. Accessed April 10, 2016

34. Centers for Medicare \& Medicaid Services, Physician Quality Reporting System. https://www.cms.gov/Medicare/Quality-Initiatives-PatientAssessment-Instruments/PQRS/MeasuresCodes.html. Accessed April 10,2016 